\title{
Corrosion Process of Ductile Iron with Cement Mortar Linings as Coatings in Reclaimed Water
}

\author{
Yarong Song ${ }^{1}$, Yimei Tian ${ }^{1,2}$, Xin Zhao ${ }^{1,2, *}$, Hao Guo ${ }^{1}$, Haiya Zhang ${ }^{2}$ \\ ${ }^{1}$ School of Environmental Science and Engineering, Tianjin University, Tianjin 300350, China \\ ${ }^{2}$ Tianjin Engineering Center of Urban River Eco-Purification Technology, Tianjin 300350, China \\ *E-mail: xinzhao@tju.edu.cn
}

doi: $10.20964 / 2016.08 .37$

Received: 7 May 2016 / Accepted: 4 June 2016 / Published: 7 July 2016

Corrosion of ductile iron with cement mortar linings (CML) exposed to reclaimed water within one year was monitored by electrochemical impedance spectroscopy (EIS), potentio-dynamic polarization (PDP), scanning electron microscopy (SEM) and energy dispersive spectroscopy (EDS). The results differentiated two corrosion phases: (a) passivation and (b) initiation and propagation of corrosion. Based on the CML and CML/iron interface behavior with measured electrical properties, the study highlighted the capacitance features of CML and the growth of passive film at the interface. The CML durability was evaluated which performed well during passivation and corrosion initiation, but degraded as exposure time increased. Also, the electrochemical methods were demonstrated qualified for corrosion monitoring of lined iron pipes by non-destructive techniques.

Keywords: Corrosion; Ductile iron; Cement mortar linings; Reclaimed water; EIS

\section{FULLTEXT}

(C) 2016 The Authors. Published by ESG (www.electrochemsci.org). This article is an open access article distributed under the terms and conditions of the Creative Commons Attribution license (http://creativecommons.org/licenses/by/4.0/). 